\title{
A review of wave energy estimates for nearshore shelf waters off Australia
}

\author{
Joao Morim $^{\mathrm{a}^{*}}$, Nick Cartwright ${ }^{\mathrm{a}, 1}$, Amir Etemad-Shahidi ${ }^{\mathrm{a}, 2}$, Darrell Strauss ${ }^{\mathrm{a}, 3}$, Mark \\ Hemer $^{\mathrm{b}}$ \\ ${ }^{a}$ Griffith School of Engineering, Griffith University, Gold Coast, Southport, \\ Queensland 4222, Australia, Tel: +61 755528572 \\ E-mail ${ }^{1}$ : n.cartwright@griffith.edu.au \\ E-mail²: a.etemadshahidi@griffith.edu.au \\ E-mail ${ }^{3}$ :d.strauss@griffith.edu.au
}

${ }^{\mathrm{b}}$ Centre for Australian Weather and Climate Research: A Partnership between CSIRO and the Bureau of Meteorology, Hobart, Tasmania 7001, Australia, GPO Box 1538, Tel: +61 362325017

E-mail: mark.hemer@csiro.au

*Corresponding Author, E-mail: joao.morimnascimento@griffithuni.edu.au

\begin{abstract}
Australia is recognized as one of the most promising region in the world to harvest wave energy. In order to harness such energy it is required to perform an assessment of the available resources as a pre-requisite to accurately select and characterize sustained nearshore optimum sites of wave energy concentration called 'hotspots'. Such regions typically offer greater economic potential for sitting wave energy conversion facilities since potential trade-offs between benefits of harvested wave energy and costs of bringing energy ashore are more profitable. This article is a review of wave energy predictions performed for nearshore shelf waters off Australia. Publicly available estimates of wave energy resource are reported from the literature, providing important descriptions of nearshore wave energy resources along Australia's margin. The states of Tasmania, Victoria, Western Australia and South Australia are endowed with relatively high levels of annual average wave power, in excess of approximately $30 \mathrm{~kW} \mathrm{~m}^{-1}$ along most of the exposed coasts. Coastal and nearshore wave energy resources are found significant and fairly sustained throughout the year for most of southern Australian states, with the highest mean wave energy power observed during spring and winter. These predictions mostly derived from numerical wave models reveal averaged discrepancies of approximately 20-30\% when compared to waverider buoy records. The level of accuracy of wave hindcast
\end{abstract}


data used as boundary conditions (model input) and its suitability to describe Australia's wave climate are found to be major reasons for that disparity. The densely populated coasts of New South Wales and Queensland are also found to be potential sites for wave energy harvesting, however, they have not yet been assessed for wave energy resources in nearshore shelf waters using a high spatial resolution wave transformation model. Lastly, research using currently available WECs and Australian resource data the levelised cost of electricity (LCOE) of wave energy in the Australian southern coast has been calculated to be as low as 100 \$/MWh and the capacity factor as high as $\sim 54 \%$.

Keywords: wave energy, nearshore waters, LCOE, WEC, Australia.

\section{Introduction}

The extensive coastline of Australia's southern half is relatively well exposed to the powerful storms from the Southern Ocean and to the prevailing westerly winds contains a notable fraction of the global wave energy resources [1]. Australia's potential market for harvesting wave energy using wave energy converters (WECs) is very promising and can definitely provide a sustainable alternative for electricity generation. However, wave energy varies substantially according to local features and weather systems of each region. Therefore, it is not uniformly distributed within nearshore regions along the coast as seen in Fig. 1. In order to identify and characterize the most suitable sites for wave energy harvesting and also to select the most appropriate WEC for each region, it is required to accurately assess priority nearshore wave energy resources (e.g. [2,3]).

Former investigations have assessed Australia’s potential wave energy at several geographical and temporal scales using waverider buoy records (e.g. [4-7]) and or wave models (e.g. [8-11]) and the outcomes are suggestive of substantial wave energy resources. In order to attain appropriate measures of nearshore wave energy resource for determining the productivity of WECs, it is required to take into account the attenuation of the wave energy across the continental shelf $[13,14]$. Therefore, the usage of gross offshore wave energy estimates, as an indicator of the available wave energy resource in nearshore waters (i.e. where the WECs are typically positioned) is likely to be misleading. Significantly, until now no review of nearshore wave energy 
for Australia has been made. Amongst the available wave energy resource evaluations performed in Australia, research performed by [7-10] provides descriptions of the nearshore wave energy resource for water depths of $\leq 50 \mathrm{~m}$. These assessments are of great value and represent most of the existing available information regarding Australia's nearshore resource. Nevertheless, further assessments of nearshore wave energy resource are required by the wave energy harnessing industry for tuning of existing wave energy converters and planning of future WEC deployments. This will enable researchers to assess more accurately the potential of wave energy converters for coastal Australian regions.

This article is the first review of available nearshore wave energy resource estimates for Australian waters. This paper builds on the work of [8-10] and a growing scientific base, which present the prospects of the Austrian nearshore wave energy resources [2,11,12]. The paper beings with a brief explanation of how wave energy resources are distributed around nearshore shelf waters off Australia. Section 3 presents the latest estimates of annual mean wave energy that have been achieved through numerical wave modelling in Australia. Section 4 discusses the natural seasonal variability of the available resources around Australia. The level of agreement between the available estimates derived from numerical wave model estimates and waverider buoy archives are addressed in Section 5. The current and future perspectives of the LCOE of wave energy in Australia are provided in Section 6, followed by a discussion and final conclusions.

\section{Australia's wave energy resources}

The southern half of Australia is exposed to relatively strong and persistent wave conditions, which are characterized by wave heights varying between around 1 to $4 \mathrm{~m}$ and wave periods of approximately 6 to $11 \mathrm{~s}$. The average $H_{\mathrm{s}}$ of swell off the southern and southwestern coasts of Australia is approximately 2 to $2.5 \mathrm{~m}$ and the mean wave periods is about $8 \mathrm{~s}$, with the direction being predominantly from the southwest (e.g. $[8,9])$. Swell off the southeastern coast of Australia has an average significant wave height of 1 to $2 \mathrm{~m}$, a mean wave period of $7 \mathrm{~s}$ and can occur either from a southeasterly or northeasterly direction [9].

It is recognised that the amount of wave energy incident along the southern coast of Australia constitutes the principal potential resource of ocean renewable energy in 
Australia [8]. The relatively high levels of wave power observed along most of the southern states of Australia are very promising (Fig. 1), however, they still pose significant challenges for engineering design. Research of Hemer and Griffin [8] provided a detailed wave energy atlas of southern Australia and calculated the total available wave energy flux propagating across the full length of the $25 \mathrm{~m}$ depth contour for the stretch of coast from $29^{\circ} \mathrm{S}$ on the West Australian coast (approximate location of Geraldton, WA) to $148^{\circ} \mathrm{E}$ (Southern tip of Tasmania), including that part of Bass Strait, West of $148^{\circ} \mathrm{E}$, using careful model-based calculations. The total amount of annual wave energy was estimated to be approximately $1329 \mathrm{TWh} / \mathrm{yr}$ (annual median of $146 \mathrm{GW}$ ), which by itself represents around five times the energy requirement of Australia. Significantly, turning just 10\% of such energy into electricity would represent nearly one-half of Australia's total electricity consumption in 2010 [8].

Extensive coastal regions of New South Wales, southern-mid Queensland and midsouthern-mid Western Australia also hold moderate mean wave power levels and offer a reliability of wave energy resource delivery similar to Australia's southern shelf, i.e. time average between failures of $\geq 1$ month and failure durations of 1.5-2.5 days, which is indicative of fairly sustained wave energy resources, being therefore also potential regions for harvesting wave energy (e.g. [2,9,11]). Additionally, New South Wales and southern-mid Queensland exhibit little seasonal and synoptic variability of wave conditions and also have relatively small magnitude of extremes relative to mean, when compared to the southern margin of the continent $[8,9]$. These considerations are extremely advantageous since it is known that WECs are typically tuned to relatively moderate wave energy levels of $10-30 \mathrm{~kW} \mathrm{~m}^{-1}$ and excessive amounts of wave energy can cause irreversible damage and substantial downtime due to wave energy exceeding the range devices are tuned to. The Northern Territory is unsuitable for wave energy harvesting given the current wave harnessing technology, and its relative low levels of wave power as can be seen in Fig. 1 [9].

There are several specific tools and or technologies used for wave energy resource assessment. In Australia, numerical wave models and waverider buoy measurements have been preferred to estimate wave energy resources around Australia. Investigations conducted by some researchers [7-11] provide important descriptions of Australia's nearshore wave energy resources $(\leq 50 \mathrm{~m})$, especially along the southern 
margin of the continent.

\section{Annual estimates of nearshore mean wave power}

Lemm et al. [7] evaluated Perth's wave climate using a 2.5-year period (1994-1996) of non-directional 20-min wave data and reported an annual mean wave power of 48.0 $\mathrm{kW} \mathrm{m}^{-1}$, in a water depth of $48 \mathrm{~m}$ off south-west of Rottnest Island. Later, Hemer and Griffin [8] investigated the southern coast of Australia, using a high-resolution wave model called SWAN. Stationary representative wave sea-states for southern Australia, (annual and annual cycle of $10^{\text {th }}, 50^{\text {th }}$ and $90^{\text {th }}$ ) were derived from the 10-yr (19972006), 6-hourly archives of $H_{\mathrm{s}}, T_{\mathrm{p}}$, and $\theta_{\mathrm{m}}$ provided by the $1^{\circ}$ latitude x $1.25^{\circ} \mathrm{NWW3}$ (NOAA WaveWatch III) model. These wave sea-states were later downscaled to $0.01^{\circ}$ fine resolution grids for nearshore regions using SWAN wave model. The model water depth was derived from the Geoscience Australia (GA) $0.01^{\circ}$ bathymetry database, averaged over the NWW3 grid cell. Wind forcing was omitted for the nested SWAN models, since [8] considered that wave conditions were well described using forcing from swell boundary conditions only as Australia's southern wave climate is fairly unimodal and dominated by remotely generated waves. Time series of wave energy flux, were calculated at all NWW3 grid points in the domain 110 $155^{\circ} \mathrm{E}, 30-45^{\circ} \mathrm{S}$. Hemer and Griffin [8] reported an annual median wave power along most of southern coast of Australia at water depths of $25 \mathrm{~m}$ of approximately 50 $\mathrm{kW} \mathrm{m}^{-1}$ (Fig. 2).

Research performed by the Sustainable Energy Authority Victoria [10] along the Victorian coast (including the Bass Strait) was likewise performed using the highresolution wave model MIKE21 SW. The model was run using 1-yr (2003), 12-hourly archives of $H_{\mathrm{s}}, T_{\mathrm{p}}$, and $\theta_{\mathrm{m}}$ from the $0.125^{\circ}$ resolution AusWAM model. The hindcast data was supplied on a fixed grid extending from $140^{\circ} \mathrm{E}$, just west of the Victoria/South Australia border to $151^{\circ} \mathrm{E}$, east of Cape Howe, including all of Bass Strait. Wind forcing was considered by [10] derived from the same hindcast archives and comprised wind speed and direction. The MIKE21 SW model was run on an unstructured grid varying from approximately $0.27^{\circ}$ resolution at the model boundaries to less than $0.0135^{\circ}$ resolution along nearshore shelf waters off Victoria. The typical annual median wave power was estimated as $40-50 \mathrm{~kW} \mathrm{~m}^{-1}$ along the majority of the western part of the Victorian coastline (west of Cape Otway) and 
approximately 45-55 $\mathrm{kW} \mathrm{m}^{-1}$ along most of Tasmania's west coast (including King Island), at water depths of $\leq 50 \mathrm{~m}$. The annual median wave power in the central Bass Strait was found to be $15-20 \mathrm{~kW} / \mathrm{m}$ along the coastline between Phillip Island and Wilson's Promontory. East Gippsland observed an annual median wave power of approximately $10-15 \mathrm{~kW} / \mathrm{m}$.

Hughes and Heap [9] also presented nearshore wave energy estimates, however they were obtained from a regional scale wave model, which neglected shallow water physics. The AusWAM model was run at $0.1^{\circ}$ resolution on a regular grid covering 110-156 ${ }^{\circ}$ longitude and $7-46^{\circ}$ latitude for an 11-year period (1997-2008), forced with 6-hourly archives of $\mathrm{Hs}, \mathrm{Tm}$ and $\theta \mathrm{p}$ from the $0.5^{\circ}$ version of AusWAM. Wind forcing was not considered by [9] and the bathymetry was obtained from the topographic data of Geoscience Australia at a resolution of $0.0225^{\circ}(\sim 2.5 \mathrm{~km})$. This research revealed typical annual mean wave power of approximately $25-35 \mathrm{~kW} \mathrm{~m}^{-1}$ and $10-20 \mathrm{~kW} \mathrm{~m}^{-1}$ along most of the southern, southwestern and eastern coastlines of Australia $(\leq 50 \mathrm{~m})$, respectively. The models details' used by [8-10] to estimate wave energy resources around nearshore shelf waters off Australia are shown in Table 1.

Table 2 shows nearshore wave energy findings from [8-10] at several locations along the Australian coastline ( $\leq 50 \mathrm{~m})$. Comparisons with other coastal regions of the world show that the magnitude of the nearshore wave power in these areas (excluding the Northern Territory) is indicative of a significant resource. For instance, the Hawaiian Islands in the North Pacific Ocean and the southwestern coastline of Great Britain in the Northern Atlantic Ocean, described as being subject to a very strong wave climates, experience annual wave power between $15-25 \mathrm{~kW} \mathrm{~m}^{-1}$ [15] and $20 \mathrm{~kW}$ $\mathrm{m}^{-1}[16]$ in nearshore waters $(\leq 50 \mathrm{~m})$, respectively.

\section{Seasonal variability of nearshore mean wave power}

The Australian wave climate varies substantially from region to region according to the regional weather systems, which have scales of $\sim 1000 \mathrm{~km}[8]$. The pattern of seasonal variability of the wave energy resource along the southern half of Australia (including Western Australia, New South Wales and South Queensland) is consistent with more energetic conditions in the winter seasons and less energetic conditions in the summer seasons $[9,17]$. This pattern coincides with the seasonal wind patterns, which is (in broad terms) characterized by intense temperate storms during winter, 
which generate heavy seas and swell, and local sea breezes during autumn and summer. Spring and autumn represent transition seasons, with intermediate magnitudes of monthly mean wave powers (see also [17]). The pattern of seasonal variation along the northern half of Australia (excluding the northeast coast) is consistent with more energetic wave conditions during winter and summer, which coincides with the peak of the SE Trade Winds and the occurrence of tropical cyclones respectively.

Table 2 shows the seasonal variation of mean wave power observed by [8] and [9] for Cape Sorell (Tasmania), Augusta (Western Australia) and Pelican Point (South Australia) represented in Fig. 1. The seasonal mean wave power presented by [10] is not included in Table 2, since detailed information regarding the exact locations of the estimates and their precise magnitude were not provided. The largest variations of wave power throughout the year are observed at Cape Sorell and Augusta. Considerable differences in the mean wave power are seen between autumn/summer and spring/winter seasons at these locations (Table 2). The seasonal variability of wave power at Pelican Point records less variations of mean wave power within seasons with a more uniform pattern. Nevertheless, the relative magnitudes of mean wave power to annual mean wave power along the southern coastline of Australia are considerable and more significant during spring and winter [8].

\section{Reliability of available numerical wave model predictions}

The modeled nearshore wave energy estimates provided by [8-10] show different levels of agreement when compared to long-term waverider buoy archives. Hemer and Griffin [8] wave energy estimates are reported to be approximately 20\% greater than estimates from available waverider buoy records averaged over all three available sites (Cape Naturalist, Cape du Couedic, Cape Sorrell), as shown in Table 2. These estimates exceeded waverider buoy estimates by a considerable margin of $13 \%-53 \%$ when waves are small $\left(10^{\text {th }}\right.$ percentile) and by a significant margin (2\%$29 \%$ ) at other times ( $50^{\text {th }}$ and $90^{\text {th }}$ percentiles), as shown in Fig. 4 . This overestimation of wave energy was shown to be consistent with a $5 \%-10 \%$ overestimation of $H$ s observed at deep water sites, where a comparison between model values (effectively at the boundaries of the SWAN nested models at which NWW3 input data were specified) and satellite altimeter data was carried out [8]. 
Hemer and Griffin [8] therefore attributed the percentage error ${ }^{1}$ of $20 \%$ to the $5 \%$ $10 \%$ overestimation of $H$ s by the NWW3 model in the region.

In contrast, the AusWAM run by Hughes and Heap [9] underestimated by a considerable margin of approximately 50\% the aforementioned nearshore wave energy estimates of Hemer and Griffin [8], as shown by Table 2. Nevertheless, no attribute data quality across the model domain was performed by [9]. As mentioned before, Hughes and Heap [9] used wave hindcast data from the AusWAM model as model input, which was previously found to have less success than NWW3 model in simulating observed $\mathrm{Hs}$ at the location of Australian waverider buoys. Work of Hemer, Church and Hunter [15] observed that the AusWAM datasets consistently underestimates large wave events, particularly in the Southern Ocean, exhibiting much greater discrepancy from waverider buoy measurements than the NWW3 model, as observed in Fig. 5. This is in agreement with research of [10], which also found that $H$ s values from the AusWAM hindcast data for 2003 were approximately 15.5\%, 12.9\% and 5.1\% lower than the measured Hs at Cape Sorell, Cape du Couedic and Point Lonsdale, respectively. It is hence reasonable to consider that the underestimation of wave energy observed by [9] along Australia's southern coast (particularly at the waverider buoy sites) is clearly associated with the underestimation of the Hs by the AusWAM datasets.

Regarding the wave energy estimates of [10] obtained from the MIKE21 SW model, it is not possible to evaluate their accuracy, since they were not compared with estimates from waverider buoy data. Instead, [10] only investigated the ability of its model to simulate $H$ s by comparing these results with waverider buoy records of $H s$ at the available sites (Portland, Port Lonsdale, Cape Sorell). These estimates are reported to adequately simulate waverider buoy measurements of $H$ s at Portland (VIC) and Cape Sorell (TAS) and to slightly overestimate at Point Lonsdale (VIC).

Unfortunately, the adequate representation of the measured $H$ s by the model does not ensure an equivalent performance in the simulation of wave energy, since the latter is a function of $H$ s squared and wave period (e.g. [3]) and therefore any possible assumption could be misleading.

As formerly shown, different levels of agreement between numerical wave models and waverider buoys are strongly related with the quality and resolution of the initial wave inputs given to the models (i.e. boundary conditions). These differences are also 
associated with the temporal and spatial resolution of the chosen numerical models and their ability to resolve relevant details of the wave field over complex bathymetries in shallow waters (see Table 1). The regional AusWAM model is known to be inappropriate to estimate wave energy resources nearshore (i.e. due to its limited shallow water physics and limited grid resolution compared to the increased bathymetry complexity in shallow waters. On the other hand, the high-resolution models SWAN and MIKE21 SW are capable of resolving relevant details of the wave field and accounting for the entire shallow water physical processes, e.g. friction effects and refraction (Table 1). Therefore, the AusWAM estimates presented by [9] are of limited value for an accurate description of the wave energy resources in nearshore shelf waters, as mentioned by [9].

\section{The performance and cost of wave energy production in Australia}

It has been previously shown that the potential of wave energy reaching nearshore shelf waters off Australia is not limited by physical resource quality, especially along the southern half of the continent and that most of these resources are reasonably close to population centers and potential industry users [7-12]. In order to understand the potential extent of use of the Australian resources, Behrens et al. [2] and Behrens [11] assessed some WECs potential in Australian coastal regions, using different methodologies.

In 2011, Behrens et al. [2] used wave energy data from the Australian Renewable Energy Atlas to spatially evaluate the performance of three different types of WECs and determined the lowest cost per MWh possible at locations around the Australian coastline (water depths of $\sim 30 \mathrm{~m}$ ). These devices have publically available data from trials and they fall into different classifications, namely point absorbers, terminators and linear attenuators. Later, Behrens et al. [11] evaluate the performance and energy that could be generated annually by a number maximum of hypothetical wave farms (terminators) deployed along the full length of the $25 \mathrm{~m}$ depth contour from South Australia to Queensland ( $5700 \mathrm{~km}$ ), based on wave energy data from the NWW3 model archives. The results confirmed that the available nearshore wave energy resources of Australia are of sufficient magnitude to make a significant contribution to electricity generation in Australia given the current wave technology. One of the standard metrics used to understand the potential extent of use of any WECs is the 
capacity factor ${ }^{2}$. As known, the average energy production from any wave energy technology has a large effect on the LCOE, and thus the uptake of that technology.

In Australia, Behrens et al. [2] estimated a net capacity factor $k$ of $21.3-54.3 \%$ and a LCOE of \$78.2-261.0/MWh for all three WECs along the southern coast, which is along with the west coast of Tasmania the regions with the lowest LCOE ( 100 \$/MWh). Significantly, the LCOE of the terminator along Western Australia, Victoria and Tasmania was seen to be less than \$95/MWh (Fig. 6). Similarly, Behrens et al. [11] observed a $k$ of $26-44 \%$ for the hypothetical terminator farms long the Victorian and Tasmanian coasts and 10-15\% along the eastern margin of the continent, ultimately generating a total average wave energy of $275 \mathrm{TWh} / \mathrm{yr}$. The outcomes from these investigations demonstrated that the average capacity factor of wave power along wide nearshore regions off Australia is comparable to that of wind power (2545\%) [22], which increases the likelihood of large capacity ( 500GW) wave farms being deployed. Also, it seems that the LCOE decreases towards more southern latitudes since the wave power available is much greater, which makes the LCOE of specific WECs for southern Australia are comparable to the costs of other renewable technologies such as wind and solar [2,23], as shown in Fig. 6.

\section{Conclusions}

Wave energy has the potential to make a significant contribution to electricity generation in Australia [12]. The nearshore wave energy resource is significant and fairly sustained throughout the year along the southern coastline of Australia, with the highest mean wave powers observed during spring and winter.

The level of accuracy of the different hindcast wave data used by [8-10] (temporal and spatial resolution) and its suitability to describe the Australian wave climate are shown to have significant impact on the accuracy of wave energy estimates provided by the numerical models. Subsequently, potential investigations of Australia's nearshore wave energy resources should be strongly observation dependent in order to enable, for example, a proper calibration and verification of numerical wave models. A high spatial resolution wave transformation model with time-variable boundaries and local wind conditions should also be regarded as the next step to properly resolve resource for reconnaissance, feasibility and design applications. Furthermore, it has been documented that mean wave characteristics demonstrate high levels of 
interannual variability (changes in monthly or annual mean values from year to year) and are subject to long-term decadal changes (changes in mean values over a number of years), which necessarily imposes limitations on the accuracy to which wave energy can be envisaged over time. Consequently, upcoming wave energy resource assessments should be based on validated historical records of at least 10 years to make sure wave resource variability and related aleatory uncertainty are properly quantified over several different time scales, which are relevant to wave energy production. Characterizations of the wave energy resource in terms of sea states, i.e. $H_{\mathrm{s}}, T_{\mathrm{e}}$ (energy period) and $\theta_{\mathrm{m}}$ should be presented so that it is possible not only to choose the most appropriate WEC for a given area but also tune existing wave energy converter designs $[3,20]$, ultimately reducing levelised cost of electricity (LCOE). Details of threshold exceedances above and below which a device fails to operate should also be provided to enable a complete assessment of the suitability of the wave energy resource for site-specific locations for specific devices.

Hughes and Heap [9] is the only assessment that assessed nearshore wave energy recourses along the coasts of New South Wales, Queensland and Western Australia. However, [9] report is a national-scale assessment of the Australian resource rather than a detailed characterization of wave energy resource in nearshore waters. Assessing these regions using a high-resolution shallow water model and an appropriate hindcast wave data will certainly provide more accurate descriptions of the nearshore wave energy resource. Also, the coasts of New South Wales and Queensland hold numerous Waverider buoys that could be used to properly calibrate and validate numerical wave models. The national electricity grid is also well established along these margins and could allow easy integration of the wave generated electricity.

Lastly, it is recognised that wave energy technology needs to reduce its LCOE in order to become more competitive against other sources of renewable such as wind and solar energy. Financial analysis has shown that wave energy becomes economically viable when capital cost and operations and maintenance costs (O\&M) are reduced, reducing significantly the LCOE. A considerable part of the capital cost (besides the cost of the device itself) is the anchorage/mooring as shown in Fig. 7, which varies by device [24]. There are currently a wide variety of WEC designs being explored in order to reduce these costs. There also appears to be the opportunity to 
find the right balance between size of equipment, anchorage expenditure and number of units per wave farm [12]. Achieving technological maturity will also require careful planning to ensure wave farms are located for optimal wave energy conversion, minimal environmental impact and where possible providing useful synergies with environmental management and with other users of ocean resources. There is little doubt that is the economics of energy extraction, maintenance, transmission, environmental and social impacts that will determine the future of wave energy in Australia and not (only) the extent of the Australian resource [12].

\section{Superscript letters:}

Page 7, Chapter 5, line 12

${ }^{1}$ calculated as $100 \times[($ model-buoy $) /$ buoy $]$.

Page 9, Chapter 6, line 19

${ }^{2}$ is the actual yearly electrical energy output of wave farm (or converter) divided by the electrical energy produced if the plant was operated at rated power continuously during the entire year. 


\section{References}

[1] Gunn K, Stock-Williams C. Quantifying the global wave power resource. Renewable Energy 2012;44:296-304.

[2] Behrens S, Hayward J, Hemer M, Osman P. Assessing the wave energy converter potential for Australian coastal regions. Renewable Energy 2011;43:210-217.

[3] Iglesias G, Carballo R. Choosing the site for the first wave farm in a region: A case study in the Galician Southwest (Spain). Energy 2011;36:5525-5531.

[4]. Wright LD. Nearshore wave-power dissipation and the coastal energy regime of the Sydney-Jervis Bay region, New South Wales: a comparison. Australian Journal of Marine and Freshwater Research 27(4) 633 - 640. Published: 1976

[5] Short AD, Trenaman NL. Wave climate of the Sydney region, an energetic and highly variable ocean wave regime. Australian Journal of Marine and Freshwater Research 1992;43:765-91.

[6] Reid JS, Fandry CB. Wave climate measurements in the Southern Ocean. Tech. Rep. 223. Hobart, Australia: Commonwealth Scientific and Industrial Research Organisation (CSIRO); 1994.

[7] Lemm AJ, Hegge BJ, Masselink G. Offshore wave climate, Perth (Western Australia), 1994-96. Marine and Freshwater Research 1999;50:95-102.

[8] Hemer M, Griffin D. The wave energy resource along Australia’s southern margin. Journal of Renewable and Sustainable Energy 2010;2(043108):15. doi:10.1063/1.3464753.

[9] Hughes MG, Heap AD. National-scale wave energy resource assessment for Australia. Renewable Energy 2010;35(8):1783e91. doi:10.1016/j.renene. 2009.11.001. 
[10] Sustainable Energy Authority. Wave and Tidal Power Assessment for the Victorian Coastline. Technical Report N. J121/R01; October 2004.

[11] Behrens S, Hayward J, Woodman S, Hemer M, Ayre M, 2012, AEMO 100\% Renewable Energy study: Wave Energy, CSIRO, Newcastle, Australia.

[12] Hayward J, Behrens S, McGarry S, Osman P. (2012). Economic Modelling of the Potential of Wave Energy. Renewable Energy, 48, 238-250.

[13] Folley M, Whittaker TJT. Analysis of the nearshore wave energy resource. Renewable Energy 2009;34:1709-15

[14] Folley M, Whittaker TJT, Henry A, The effect of water depth on the performance of a small surging wave energy converter. Ocean Engineering 2007;34:1265-74.

[15] Stopa JE, Cheung KF, Chen YL. Assessment of wave energy resources in Hawaii. Renewable Energy 2011;36:554-67.

[16] Nieuwkoop JCC, Smith HCM, Smith GH, Johanning L. Wave resource assessment along the Cornish Coast (UK) from a 23-year hindcast dataset validated against buoy measurements. Renewable Energy 2013; 58:1-14.

[17] Hemer MA, Church JA, Hunter JR. Waves and climate change on the Australian coast. Journal of Coastal Research 2007;50:432e7. ICS2007 (Proceedings) e Special Issue.

[18] Hemer MA. A wave climatology for the Australian region. Web Based Appendix. CSIRO Marine and Atmospheric Research. January 2007.

[19] Caires S, Sterl A. 100-Year Return Value Estimates for Ocean Wind Speed and Significant Wave Height from the ERA-40 Data. J. Climate 2005;18:1032-1048. 
[20] Folley M, Cornett A, Holmes B, Lenee-Bluhm P, Liria P. Standardising resource assessment for wave energy converters. $4^{\text {th }}$ International Conference on Ocean Energy 2012 in Ireland.

[21] Saket A, Etemad-Shahidi A. Wave energy potential along the northern coasts of the Gulf of Oman, Iran. Renewable Energy 2012;40:90-7. Renewable Energy 2012;48:238-250.

[22]. Department of Environment and Heritage - Australian Greenhouse Office, National Code for Wind Farms - A Discussion Paper, May 2006, p.12

[23]. Hayward J, Graham P, Campbell P. Projections of the future costs of electricity generation technologies: an application of CSIRO’s Global and Local Learning Model (GALLM). Technical report. Commonwealth Scientific and Industrial Research Organisation (CSIRO); 2011

[24]. Osman P, Behrens S, Griffin D, Hayward J, Hemer M, Knight C, McGarry S, Wright S (2012). Ocean Renewable Energy: 2015-2050 An analysis of ocean reweable energy in Australia. CSIRO Energy Transformed and Wealth from Oceans Flagships 


\section{Figures Captions:}

Fig. 1. Maps of average wave energy flux $(\mathrm{kW} / \mathrm{m})$ for Australia. Coastal locations along the Australian coastline for which average wave energy are compared are marked with ' $\star$ '. Adapted from Hughes and Heaps [9].

Fig. 2. Maps of wave energy flux $(\mathrm{kW} / \mathrm{m})$ for Australia's southern coast at three levels, namely $10^{\text {th }}$ (top), $50^{\text {th }}$ (middle), and $90^{\text {th }}$ (bottom) percentiles (Hemer and Griffin [8]).

Fig 3. Fig. 3. Map of seasonal indices for wave energy in Australian shelf waters obtained by Hughes and Heap [9]. A value of 100 is equivalent to the annual average, values $<100$ indicate below the annual average and $>100$ indicate above the annual average.

Fig. 4. Monthly time-series comparison of wave energy flux between the SWAN model output (solid line) and the waverider buoy data (dashed line) at Cape Sorell (top), Cape de Couedic (middle), and Cape Naturaliste (bottom). Upper two curves of each plot correspond to 90th percentile values. The middle two curves correspond to the 50th percentile values, and the lower two curves correspond to the 10th percentile values (Hemer and Griffin [8]).

Fig. 5. Scatter plots of in-situ measured significant wave heights (data from all the Australian waverider buoys) against estimated ones from NWW3 and AUSWAM models [15].

Fig. 6. Bivariate distribution for unitless capacity factor (right column) per annum and LCOE (\$/MWh) of a point absorber (Device 1), terminator (Device 2) and linear attenuator (Device 3) around Australia. Modified from Behrens et al. [2].

Fig. 7. Annual levelised cost of electricity breakdown. 


\section{Tables Captions:}

Table 1. Summary details listed for numerical wave models and hindcast data used to estimate wave energy resources in Australian shelf waters.

Table 2. Annual wave power estimates $(\mathrm{kW} / \mathrm{m})$ derived from numerical wave models and waverider buoy (when available) at specific nearshore sites ' $\star$ ' on the Australian coastline.

Table 3. Seasonal wave power estimates $(\mathrm{kW} / \mathrm{m})$ at specific nearshore sites ' $\star$ ' on the Australian coastline. 
Figure 1




Figure 2 
Figure 2
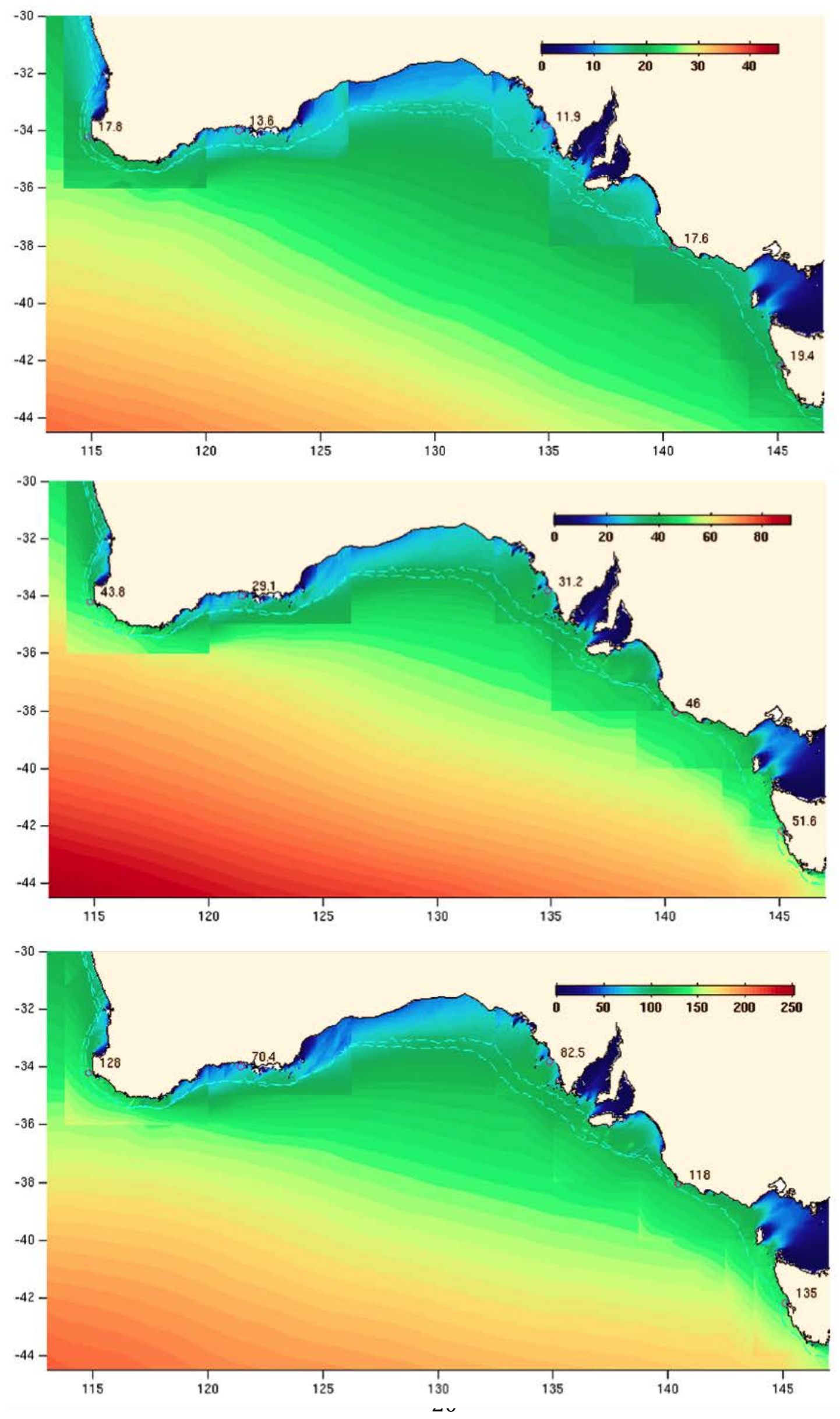
Figure 3
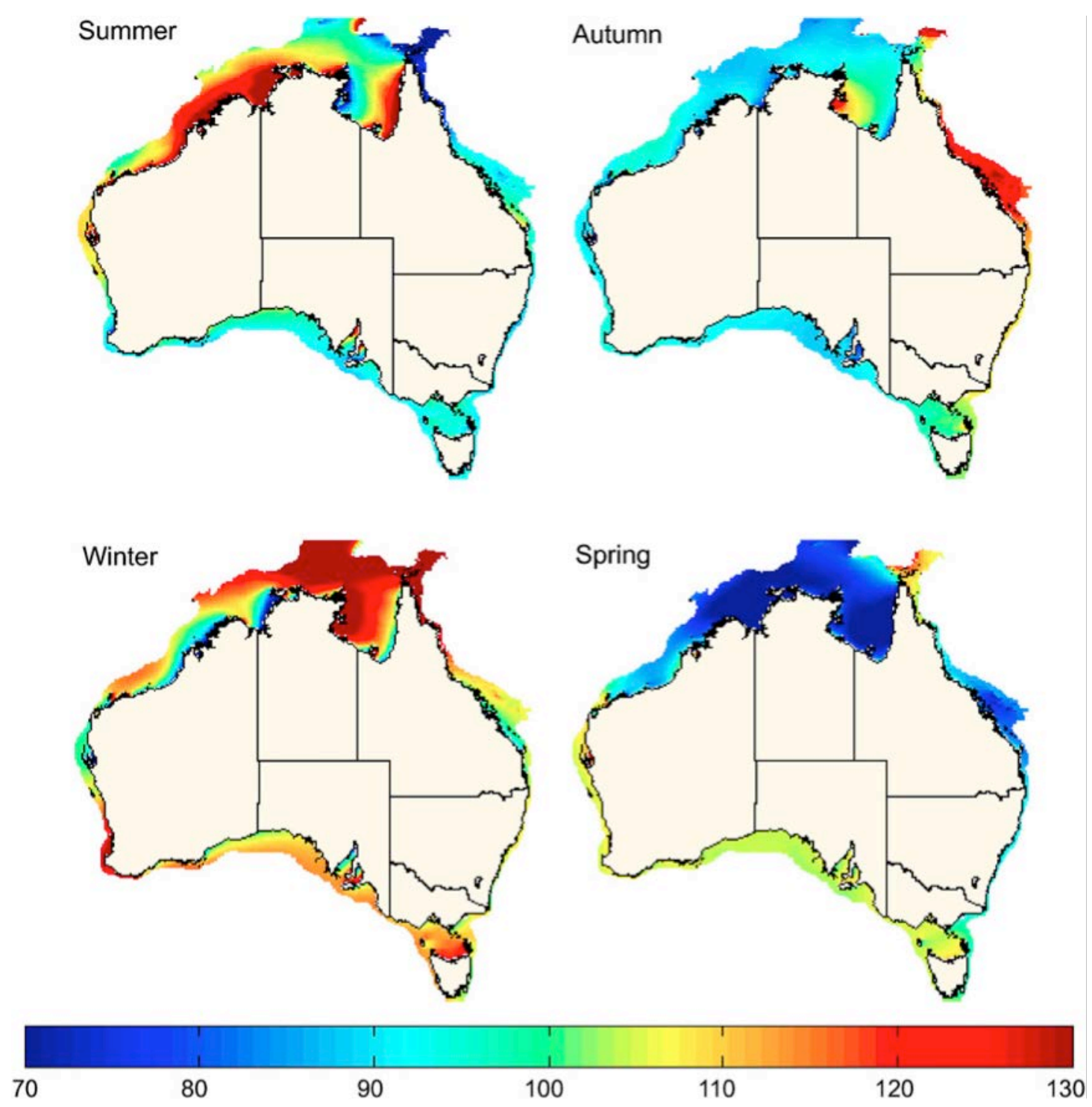
Figure 4
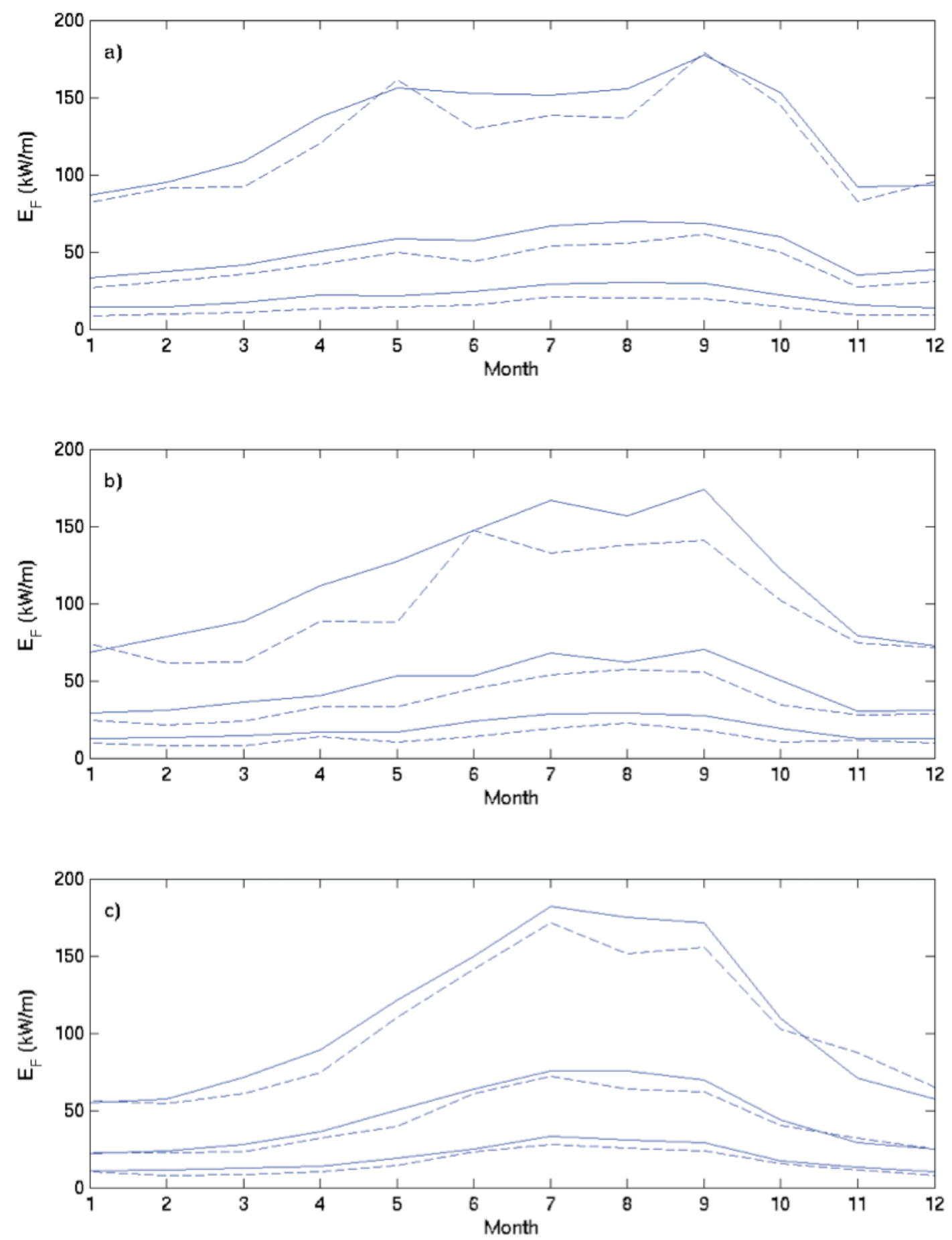
Figure 5
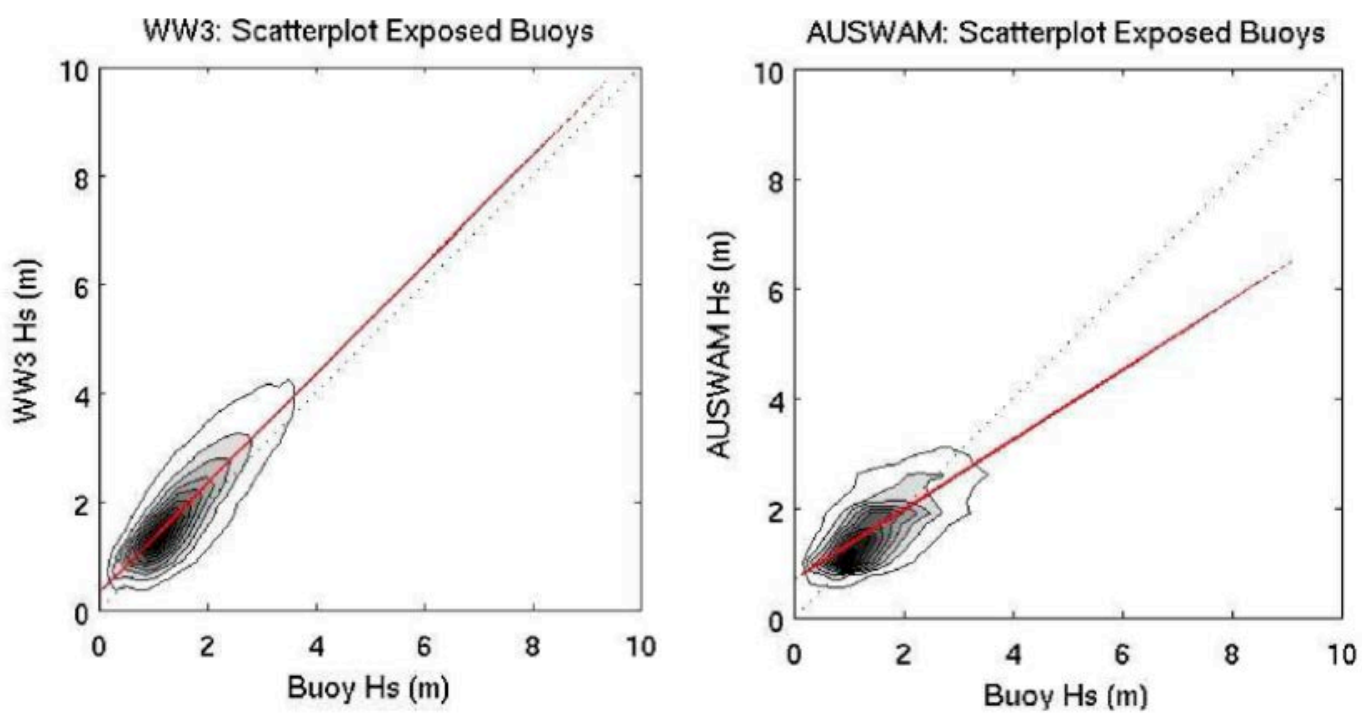
Figure 6
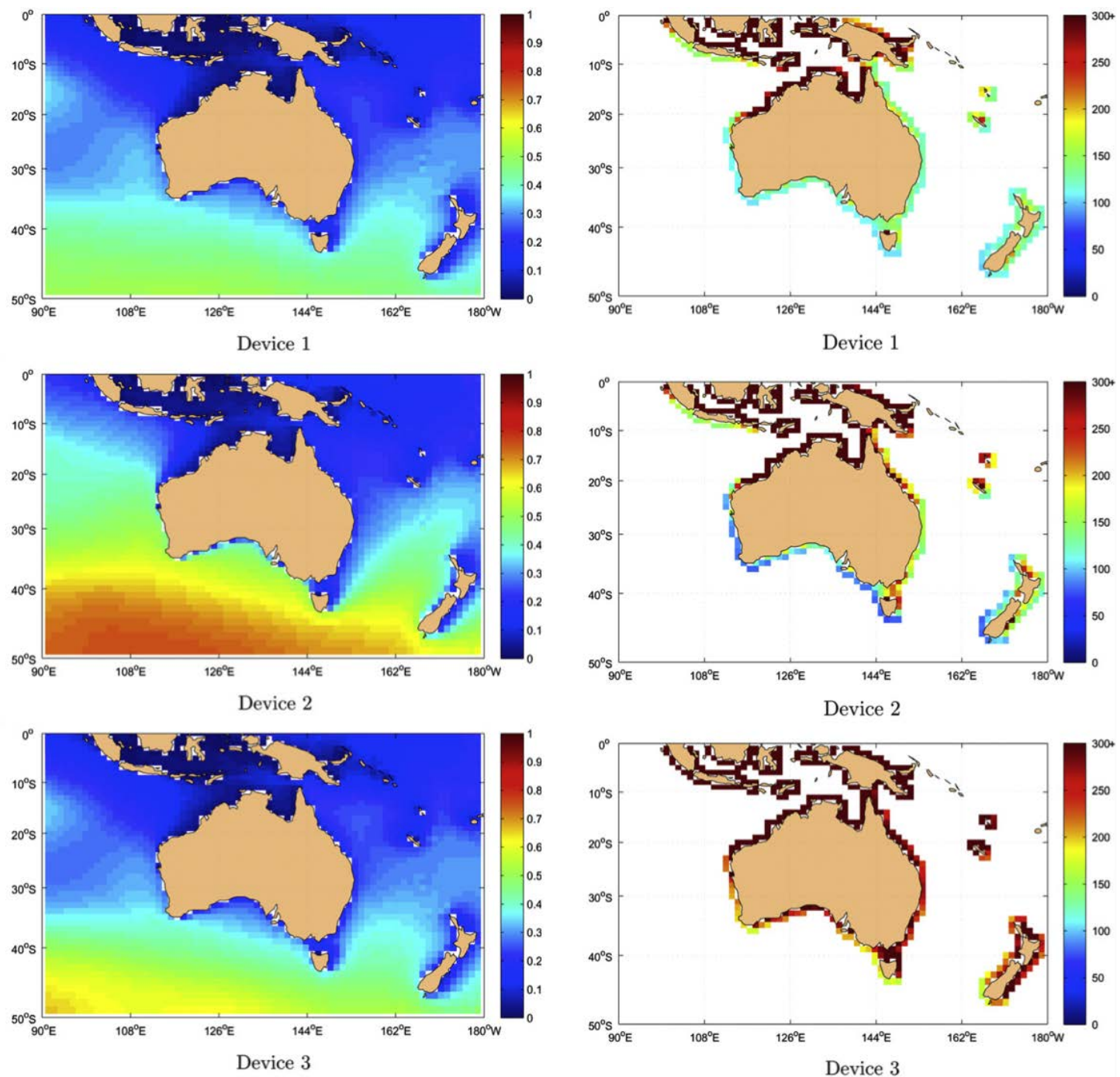
Figure 7

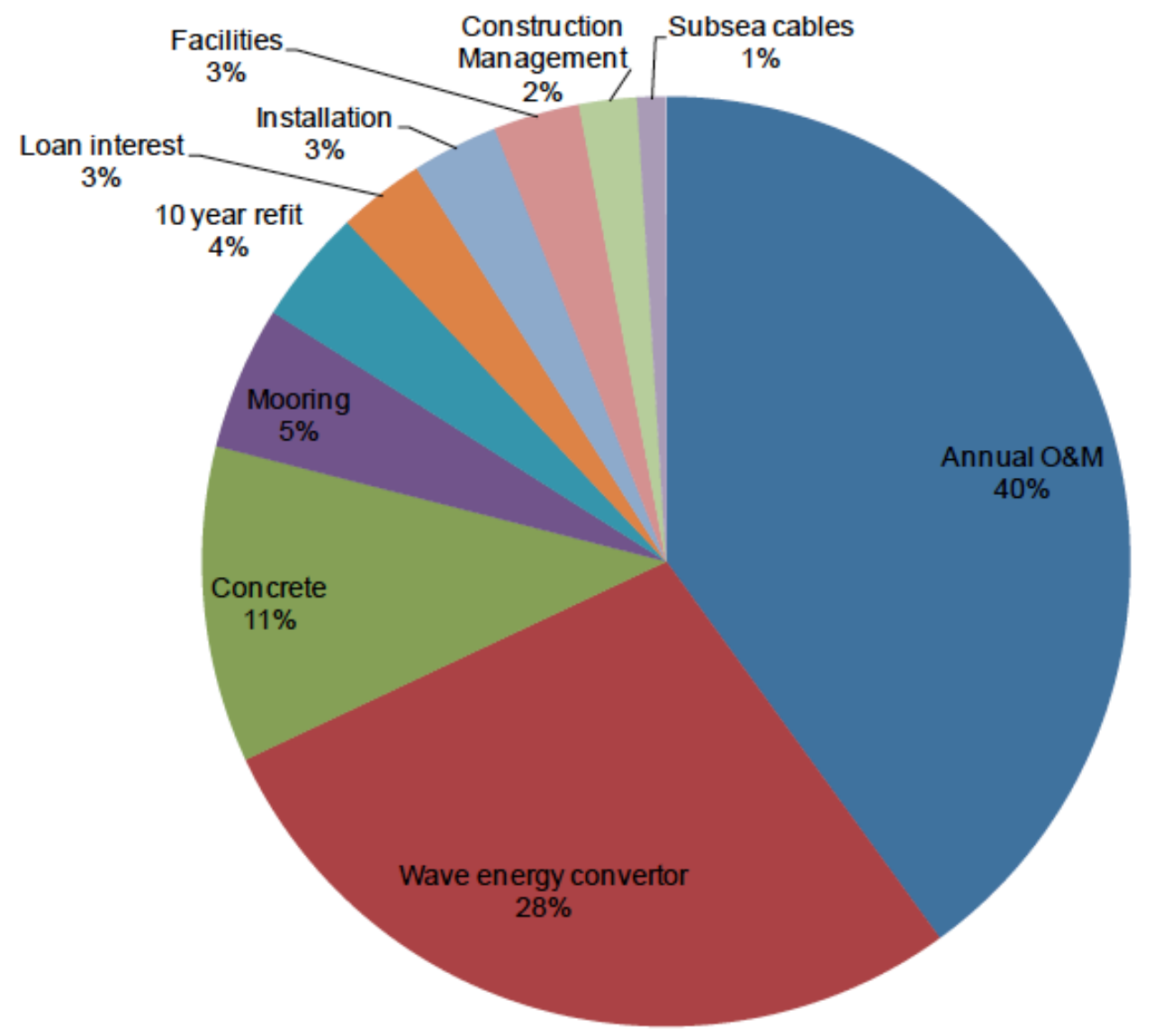


Table 1

\begin{tabular}{llll}
\hline Reference & Hemer and Griffin [8] & Hughes and Heap [9] & Sustainable Energy Authority [10] \\
\hline Model & SWAN & AusWAM & MIKE 21 \\
Mode & Stationary & Non-stationary & Non-stationary \\
Period & $1997-2006$ & $1997-2008$ & 2003 \\
Computational grid & Structured & Structured & Unstructured \\
Grid resolution & 0.05 to 001 & $0.1^{\circ}$ & $0.27^{\circ}$ to $0.0135^{\circ}$ \\
Model size & $110-148^{\circ} \mathrm{E}$ & $110-156^{\circ} \mathrm{E}$ & $140-151^{\circ} \mathrm{E}$ \\
& $29-44^{\circ} \mathrm{S}$ & $7-46^{\circ} \mathrm{S}$ & $37-42^{\circ} \mathrm{S}$ \\
Model input & Wave & Wave & Wave/Wind \\
Data source & Global NWW3 & Regional AusWAM & Meso-scale AusWAM \\
Type of data & $\left(H_{\mathrm{s}}, T_{\mathrm{p}}, \theta_{\mathrm{p}}\right)$ & $\left(H_{\mathrm{s}}, T_{\mathrm{m}}, \theta_{\mathrm{p}}\right)$ & $\left(H_{\mathrm{s}}, T_{\mathrm{m}}, \theta_{\mathrm{p}}\right)$ \\
Spatial resolution & $1^{\circ} \times 1.25^{\circ}$ & $0.5^{\circ}$ & $0.125^{\circ}$ \\
Temporal resolution & 6 -hourly & 6 -hourly & 12 -hourly \\
Bathymetry & $0.01^{\circ}$ & - & $0.0225^{\circ}$ \\
\hline
\end{tabular}


Table 2

\begin{tabular}{lllll}
\hline State & Region & Hughes and Griffin [8] & Hughes and Heap [9] & Buoy data \\
\hline Western Australia & Augusta & 50 & 16 & - \\
& Cape Naturaliste & $41(+27 \%)$ & $15(-62 \%)$ & 39 \\
\multirow{2}{*}{ South Australia } & Cape du Couedic & $43(+6 \%)$ & $17(-50 \%)$ & 34 \\
& Pelican Point & 46 & 17 & - \\
Tasmania & Cape Sorell & $51(+29 \%)$ & $19(-52 \%)$ & 40 \\
New South Wales & Seal Rocks & - & 7 & - \\
Queensland & Coral Sea & - & 9 & - \\
\hline
\end{tabular}


Table 3

\begin{tabular}{lllllll}
\hline Location & $\begin{array}{l}\text { Depth } \\
(\mathrm{m})\end{array}$ & $\begin{array}{l}\text { Spring } \\
\text { (Sept.-Nov.) }\end{array}$ & $\begin{array}{l}\text { Summer } \\
\text { (Dec.-Feb.) }\end{array}$ & $\begin{array}{l}\text { Autumn } \\
\text { (Mar.-May) }\end{array}$ & $\begin{array}{l}\text { Winter } \\
\text { (June-Aug.) }\end{array}$ & Reference \\
\hline Cape Sorell & 50 & 54.1 & 36.4 & 50.0 & 63.8 & Hemer and Griffin [8] \\
(42.4S, 145.2E) & & 20.2 & 17.5 & 19.2 & 21.6 & Hughes and Heap [9] \\
Augusta & \multirow{2}{*}{46} & 52.5 & 28.2 & 43.5 & 77.6 & Hemer and Griffin [8] \\
(34.4S, 115.1E) & & 17.3 & 14.9 & 15.4 & 20.3 & Hughes and Heap [9] \\
Pelican Point & 36 & 35.2 & 21.7 & 29.9 & 44.7 & Hemer and Griffin [8] \\
(38.0S, 140.4E) & & 17.5 & 15.3 & 15.6 & 18.6 & Hughes and Heap [9] \\
\hline
\end{tabular}

